\title{
Factorial Validity and Reliability of Self-Regulation Learning Questionnaire among Undergraduate Students at University of Dammam in Saudi Arabia
}

\author{
Malek M. Jdaitawi* \\ University of Dammam, Kingdom of Saudi Arabia

Received: 24/4/2016 Accepted: 6/6/2016

\begin{abstract}
The aim of the study was to examine the factor structure of the short-version of the self-regulated learning questionnaire in a group of undergraduate students at the University of Dammam. Four factors were assumed to represent the self-regulation: concentration, time management, self-testing and study aids. Testing reliability and validity of the constructs was another aim of this study. The study sample comprised 209 students (89 females and 120 males). Student age ranged from 18-21 years. The scale had 32 items with eight items for each of the four subscales. The research examined the factorial validity and reliability for the four factors of selfregulation across gender. The short version of the self-regulated questionnaire achieved good validity and reliability, and the confirmatory factor analysis (CFA) showed acceptable values of model fit to data. Consequently, the construct was compared via univariate analysis of variance with gender as independent variable. The results indicated significant differences between males and females. The contribution of this paper is to create a valid instrument to measure student self-regulation in university setting.
\end{abstract}

Keywords: Self-regulation learning, factor structure, reliability and validity, confirmatory factor analysis, undergraduate students.

الصلدق العاملي والثبات لمقياس التنظيم الذاتي للى طلبة جامعة الدمام يـ المملكة العربية السعودية

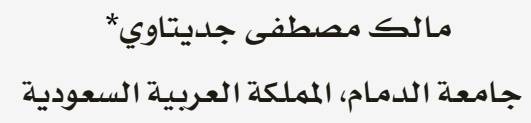

*mtmustafa@uod.edu.sa 
Over the last three decades, the field of educational psychology has experienced revolutionary changes for many reasons, such as the focus on self-regulated learning. In fact, selfregulated learning has become one of the foundations of current educational practices (Pintrich, 2000a). Nevertheless, the field lacks a solid definition of the 'self-regulated learning' construct (Boekaerts \& Corno, 2005). This is evidenced by the fact that some researchers in the field of social cognition define this construct as the proactive initiation of thoughts, feelings, and behaviors employed in a cyclical manner, according to self-production in an attempt to achieve personal aims (Zimmerman, 2000). However, Williford, Whittaker, Vitiello, and Downer (2013) view selfregulation as a capacity of the individual to appropriately manage emotions and behaviors in a specific situation. In contrast, Boekaerts (1999) incorporates affective components into cognitive components. For Boekaerts, all such components operate together on different levels of the information system. Weinstein (1994) also developed a comprehensive model related to strategic learning, but her model focuses on students as active, self-determined individuals who process information and who construct knowledge. Weinstein's model serves as the theoretical basis for the present study, illustrating the complexity of three components of learning strategies: skill, will, and self-regulation. Skill refers to the various actions or thinking processes related to the recognition of key concepts and processes and how meanings are constructed (Weinstein, 1994). Will indicates individual learning attitude, acceptance of new information, will to concentration and make efforts, and anxiety towards one's own learning performance (Tsai, 2009). Self-regulation describes how individuals manage their personal learning process, especially how to plan, monitor, focus on and evaluate their own learning (Zimmerman \& Martinez-Pons, 2001). A growing body of research has indicated that a learner's thoughts, behaviors, beliefs, or emotions facilitate the acquisition and understanding or subsequent transfer of new knowledge and skills (Tsai, 2009).

The university stage is identified as a significant development phase wherein selfregulation may indicate academic achievement (Jdaitawi, 2015) and good mental health (Boekaerts, 1993). In light of the interest of academicians in improving students' study habits, self-regulation is linked with several sets of variables, some of which are particularly evident during adolescence. In this context, adolescence seems to be the developmental phase during which the majority of changes relevant to emotional, cognitive, and behavioral adjustment are noted. First, selfregulation has been shown to be positively and negatively associated with both externalization and internalization behaviors (Kochanska \& Knaack, 2003). These behaviors can include control of attention, inhibiting behaviors, lack of ability to control negative emotions, self-monitoring, and individual affective interpretations, choices and decisions according to the environment (Rothbart, Sheese \& Ponser, 2007). Second, the construct of selfregulation has been widely associated with personality traits (Kuhl \& Fuhrmann, 2008). In fact, several researchers have stressed the significance of self-regulation in understanding personality development with respect to traits related to goals or situational expectations (e.g. Denissen, Wood, Penke, \& Aken, 2013). Hence, "personality may influence the extent to which people are pulled towards desirable outcomes and pushed to avoid potentially negative outcomes" (Robert \& Lockenhoff, 2010, p. 150). Lastly, researchers contend that self-regulation significantly influences adolescent social well-being and relationships with other individuals.

As numerous studies have indicated, selfregulation skills lead to success in and beyond university (Jdaitawi, 2015). Therefore, selfregulation constitutes an important goal in its own right (Boekaerts, 1999). However, when students enroll in higher education, they are expected to engage in more independent study time (Eccles \& Wigfield, 2002) and to demonstrate the ability to manage their learning (Ferrari, 2001). Furthermore, students are expected to use effective strategies requiring careful allocation of effort and time (Howell \& Watson, 2007). Despite the fact that enhancing self-regulation learning is currently seen as a main objective of research on adolescence, a large number of students continue to encounter difficulty regulating their learning. This is especially true for the categories of time management, concentration, and study habits (Marland, Dearlove \& Carpenter, 2015). It is therefore surprising that few studies have examined the role of students' self-regulation in 
university life (Gestsdottir \& Lerner, 2008). Similarly, according to the researchers (e.g. Vandevelde, Keer \& Rosseel, 2013; Wigfield, Klauda \& Cambria, 2011), additional studies are required. Such studies should be concerned with the implementation of selfregulated learning and assessment of varying levels of efficiency among adolescents. According to Montalvo and Torres (2004), the self-regulation learning scale still lacks sufficient construct validity. Consequently, a more valid and reliable measurement of the construct is called for. In addition, researchers (Bussing, Girke, Heckmann, Schad, Ostermann, \& Kroz, 2009) have stated that it is unclear what exactly self-regulation measures.

Therefore, the present study promises to provide a validity and reliability snapshot of the Arabic version of self-regulation learning strategies, using a large sample of students. Furthermore, despite the fact that the learning and study strategies inventory LASSI has been used previously in college settings, psychometric data is somewhat limited (Flowers, Bridges, \& Moore, 2011). Thus, the present research study aims to develop and validate such a self-regulation learning scale (shortversion) based on self-regulation study (Weinsten \& Palmer, 2002). This study also aims to assess the short version to confirm the four components (study aids, concentration, time management and self-testing) of selfregulation as the four components implemented widely in the first year education system in Saudi Arabian universities.

\section{Self-Regulation Models and Tools}

In the field of educational psychology, selfregulation learning is a critical research area and is crucial in learning enhancement. However, the premise of self-regulation is open to a multitude of interpretations based on educational philosophy. Two primary aspects of self-regulated learning have been highlighted. Specifically, the behaviorist method stresses self-monitoring, self-instruction and selfreinforcement whereas the phenomenological method emphasizes dimensions including self-worth, setting of goals, and planning. Nevertheless, the common denominator underlying the majority of these methods remains a process wherein learners themselves initiate and maintain their cognition, behaviors, and influences that lead towards the achievement of individual goals (Zimmerman \& Schunk, 2001). Self-regulation brings forth an inclusive method for student learning, and relies on factors such as cognitive, motivational, affective, and social contexts (Pintrich, 2000). Additionally, researchers propose that self-regulation is strongly influenced by conditions in the environment that motivate learners' adaptation, development and refinement of strategies, as well as their monitoring, evaluation and establishment of goals, and their planning, adoption and modifying belief processes (Hadwin, Jarvela, \& Miller, 2011, p. 68). Despite evidence showing that students can be conditioned to self-regulate themselves (e.g. Zimmerman \& Schunk, 2001), the manner in which feedback can be enhanced in terms of self-generation and external conditions is still largely untouched in literature (Nicol \& Macfarlane-Dick, 2006). Moreover, a simple definition of self-regulation has been proposed by researchers like Boekaerts, Pintrich and Zeidner (2000), Pintrich, Wolters, and Baxter (2000). Differences among the proposed models have been shown and lie in the theoretical orientation of the researchers even though several self-regulation learning aspects are held in common. The differences can be categorized as follows: purposive action towards academic achievement; self-monitoring and response; descriptions of the how and why of students' self-regulation. In this regard, Pintrich (1999) suggested four shared assumptions be put forward by self-regulation learning theories. According to Pintrich, these assumptions are the active constructive assumption, where learners actively develop their meaning, goals and strategies; the potential for control assumption, where learners may control their cognition, motivation and behavior and environment; the goal criterion, or standard assumptions that are compared against the comparisons made and that impact the possibility of change; and the mediators' assumptions, where self-regulatory activities are a way of relating the person and context to the outcomes of achievement and performance (Pintrich, 1999).

On the other hand, Zimmerman's model postulates that higher self-regulated strategy utilization is related to motivational factors like self-efficacy, effort, and personal control attributions of success or failure, and the achievement of goal orientation of the class 
and students. Both of the above models have resulted in the creation of self-regulated learning measures to evaluate student strengths/weaknesses or to predict academic success. Relevant measures include the Learning and Study Strategies Inventory (LASSI) (Weinstein \& Palme, 2002) that stems from a multi-dimensional model; the Motivated Strategies for Learning Questionnaire (MSLQ) model proposed by Pintrich, Smith, Garcia, and MaKeachie (1991); the Student Readiness Inventory (SRI) which was developed by Cengage Learning Incorporated (2012); the anticipated student adaptation to college questionnaire developed by Beyers and Goossene (2002); and the Collegiate Assessment of Academic Proficiency, CAAP. However, the present study focuses on four components of LASSI, as this was a study of preparatory (first) year students to evaluate their strengths and weaknesses for early prediction of potential difficulties with their studies. The instrument was used because it was developed specifically for university settings. The current study focused on specific components of LASSI, which are related to the self-regulation activities implemented among preparatory year students, including self-testing, study skills, time management, and concentration. Finally, as recent research stresses the importance of self-regulation, the current study provides a contribution to research on the learning and study skills inventory. As such, this is the first investigation to critically examine the use of these instruments in the context of classroom sessions with Saudi preparatory (first-) year students in particular.

\section{Method}

This study employed the quantitative analysis method, as it is the most suitable method that can appropriately handle the purpose and the problem statement of the study. Neuman (2004) stated that the survey method is most widely used for gathering data in the social sciences.

\section{Sample and Procedure of the Study}

The study sample was obtained with the help of a convenience sample comprised of 209 Saudi students enrolled at the University of Dammam. Mugera (2013) described this type of sampling as it is very easy to carry out with few rules governing how the sample should be collected, the cost and time required are smaller than other samples as well as convenience sample may help researcher gather useful data that would not have been possible using other types of sampling. However, the students were divided into study programs for different study tracks, namely health, engineering and science. Data collection was conducted among the students at the end of the second semester of 2014/2015. Students were requested to fill out the questionnaires at the end of the timetable session (30 minute) by a group of experts prior to which the study purpose was explained. The study sample comprised 209 students (89 females and 120 males) with age ranging from 18 to 21 . Based on the available data, and since the researcher plans to use structural equation modeling (SEM) as a statistical analysis tool for the current study, the researcher will follow Hair, Black, Babin, and Anderson (2010) as a guideline for appropriate sample composition. This decision is grounded on the basic recommendation of a minimum sample size of $200-250$ as being adequate for analysis in structural equation modeling (Hair et al., 2010).

Table 1

\begin{tabular}{lcc}
\multicolumn{3}{c}{ Demographic Characteristics of the Sample } \\
\hline Gender & Count & Percentage \\
\hline Females & 89 & 42.6 \\
Males & 120 & 57.4 \\
Age & & \\
$18-19$ & 140 & 67.0 \\
$19-20$ & 46 & 22.0 \\
$20-21$ & 23 & 11.0 \\
\hline
\end{tabular}

\section{Short-scale development procedures}

The researcher developed a short-version of the self-regulation learning questionnaire adopted from Weinsten and Palmer (2002) on the basis of the statistical results of prior research among adolescents (e.g. Kirby, Silvestri, Allingham, Parrila, \& Fave, 2008). In this study, emphasis was placed on one component of the four original LASSI components, namely self-regulation, because this component and its elements are present in distinct academic situations and lead to effective and efficient learning (Everson, Weinstein, \& Laitusis, 2000).

In the present study, self-regulation is defined as the student's capacity to control and manage learning. Moreover, distinct aspects of self-regulation assist in developing invaluable learning goals, in gaining control to achieve learning goals, and in employing a systematic study approach and a useful kind of helpseeking. For instance, students who are selfregulated know how to manage their time in 
completing various academic tasks in order to achieve learning goals. Accordingly, this study adopted self-regulation as the single component of LASSI. Specifically, the self-regulation scale is comprised of a 32-item self-report measure of self-regulation learning that consists of four elements, with every element containing 8 categories. The first element is concentration. This element functions to assess the students' ability to focus attention and steer clear of distractions during tasks. For example: "If I get distracted during class, I am able to refocus my attention / my mind wanders a lot when I study". Time management is considered in this study as the extent to which students develop and use schedules for the management of their responsibilities, "I find it hard to stick to a study schedule / I set aside more time to study the subjects that are difficult for me"; while self-testing is considered as the student's awareness of the significance of self-testing and revision during learning, and utilizing such practices, "I always make up possible test questions and try to answer them / I stop periodically while reading and mentally go over or review what was said". Finally, the study aids element is defined as the ability of the students to utilize or create study aids that assist in the process of learning, "My underlining is helpful when I review text material / I try to find a study partner or study group for each of my classes" (Weinsten \& Palmer, 2002).

The instrument, known as the Learning and Study Strategies Inventory (LASSI), consists of 32 items and scores are registered on a five options variance from a score of 1 , "not at all typical of me" to 5, "very much typical of me." The entire statistical procedure was analyzed through SPSS 14.0 and AMOS 7. The steps included, first, translation into Arabic, since the instrument items were originally constructed in English, and the language of the subjects is Arabic. Second, a pilot study was carried out in order to identify the clarity and readability of the questionnaire and to test the internal consistency and validity of the measure. Data from 40 students was collected and used in the pilot study as recommended in previous study such as Browne (1995), Dogan and Cetin (2009), and Sabawi (2007). The result of Cronbach Alpha of the self-regulation instrument and its dimensions was proven to be reliable and valid in the pilot study data. Hence, the psychometric properties of the four selfregulation components were then assessed on the basis of the same procedures that were used previously in measure development. The researcher conducted Cronbach alpha, splithalf methods for factor reliability and content validity and construct validity through confirmatory factor analysis for factor validity method.

\section{Results}

\section{Content analysis and reliability}

The content validity of the questionnaire was evaluated by two referees who are teaching at university, and it was judged appropriate to meet the needs of the present investigation. The questionnaire was then translated into Arabic, and was evaluated by two referees of Arabic origin who were then teaching English and Psychology at the University of Dammam. The questionnaire then was evaluated by five referees who specialized in educational fields and educational psychology. The suggestions of the referees were then incorporated into the final Arabic version and were then back translated into English. The back translated version was also compared and contrasted with the original English version, and the two versions were found to match. Analysis of data began with the examination of the data normality and outlier through a look at its distribution. The Mahalanobis, skewness and kurtosis tests were used to examine the outlier and normality analysis, and the results showed no abnormal cases. Obtained from 209 students, the internal consistency (Cronbach Alpha) reliability coefficient was .97 for the self-regulation learning strategies and the subscales ranged from .89 to .93 indicating adequate reliability (Nunnally, 1978) (Table 2 shows the results). In the reliability study conducted by the LASSI split-half method, the reliability coefficient was .94 for the whole scale. As for subscales, reliability coefficient was .85 for the "concentration", .92 for the "time management", .88 for the "self-testing", and .90 for the "study aids" subscales. Furthermore, the result of internal consistency for the self-regulation and its subscales was performed through correlation coefficients and the results ranged from .74 to .81 . On the basis of the subscales and total scales of the mean scores, the sample has an overall good use of self-regulation strategies in their learning process as shown in 
Table 3.

\section{Confirmatory factor analysis}

A confirmatory factor analysis (CFA) was conducted making use of the maximum likelihood estimation in an attempt to examine the short version fit. The model was then examined for data adequacy with the help of many adjustment measures, including the comparative fit index (CFI), the goodness of fit index (GFI), the root mean square of approximation (RMSEA) and ratio chi-square statistics/degree of freedoms $\left(\chi^{2} / d f\right)$. Based on relevant literature, the chi-square is the most extensively used goodness of fit test that evaluates the model adjustment (Albright \& Park, 2009). According to Byrne (2001), the chisquare values ranging from 2.00 to 5.00 are acceptable owing to the high sensitivity of the test relative to the size of the sample. The model adequacy relative to the independent model was assessed through CFI and TLI, while the GFI value conducted an assessment of the relative level of variance and covariance explained by the model. Moreover, this study made use of the RMSEA to assess the adjustment discrepancy between the estimated and observed matrices as recommended by Byrne (2001). CFA was also carried out to assess the overall measures acceptability using the criteria that values equal to or lower than 0.80 indicate a good model fit and those lower than 0.60 indicate a very close fit as recommended by Hair et al. (2010) with the ratio less than 5 , TLI higher than 0.90, and CFI higher than 0.90 (Kelloway, 1998; Hair et al., 2010; Huang, 2007; Kline, 1998;). Meanwhile, a factor loading significance of 0.50 is followed in order to identify if the factor structure is consistent with pri- or studies including Hwang (2007), Kelloway (1998), and Hair et al. (2010). The initial analysis revealed that 7 items loaded less than the suggested value as well as being less than .30 for items correlation. In other words, a poor fit measured model shows that those items load very low, and show high value of MI more than .80 and fit indices were not achieved $(\mathrm{RMSEA}=.083, \mathrm{CFI}=.870$, and $\mathrm{TLI}=.840)$. Therefore, those items were omitted. After deleting the 7 items, and covariate between two indicators such as (concentration 3 and 4 and time management 5 and 6), the results of the analysis revealed that the model achieved the suggested values, as shown in Figure 1; specifically, measurements revealed an acceptable value of ratio of 2.249, RMSEA value of 0.077 which was lower than 0.08 (Steiger, 1990), while the CFI value of 0.915 is within the suggested value parameters of 0.90 . The TLI value of 0.905 exceeds the suggested minimum value of 90 (Kelloway, 1998). These fit indices prove that the model fit data.

\section{Invariance across gender}

The four-factor model was then fitted to data after omitting the seven items and the fit indices improved markedly with the multisampling analysis. The results of fit indices model for male indicated to be valid with (CFI = 0.859 , TLI $=0.840$, and RMSEA $=0.087)$. With factor loadings constrained to be above 0.40 . In addition, the results of fit indices model for male indicated to be valid with (CFI $=0.847$, TLI $=0.822$, and RMSEA $=0.09$ ). With factor loadings constrained to be above 0.40 . That is, the structure of self-regulation is similar in males and females students. Hence, it can be used for research and assessment purposes.

Table 2

Descriptive Statistics and Reliability Values for the SRL subscales and total scores

\begin{tabular}{lcccccc}
\hline \multicolumn{1}{c}{ Subscales } & No. of items & Mean & SD & Min & Max & Alpha \\
\hline Concentration & 8 & 3.34 & .909 & 1 & 5 & .90 \\
Time Management & 8 & 3.27 & .931 & 1 & 5 & .91 \\
Self-Testing & 8 & 3.20 & .921 & 1 & 5 & .89 \\
Study Aids & 8 & 3.23 & .977 & 1 & 5 & .93 \\
Self-Regulation & 32 & 3.27 & .867 & 1 & 5 & .97 \\
\hline
\end{tabular}




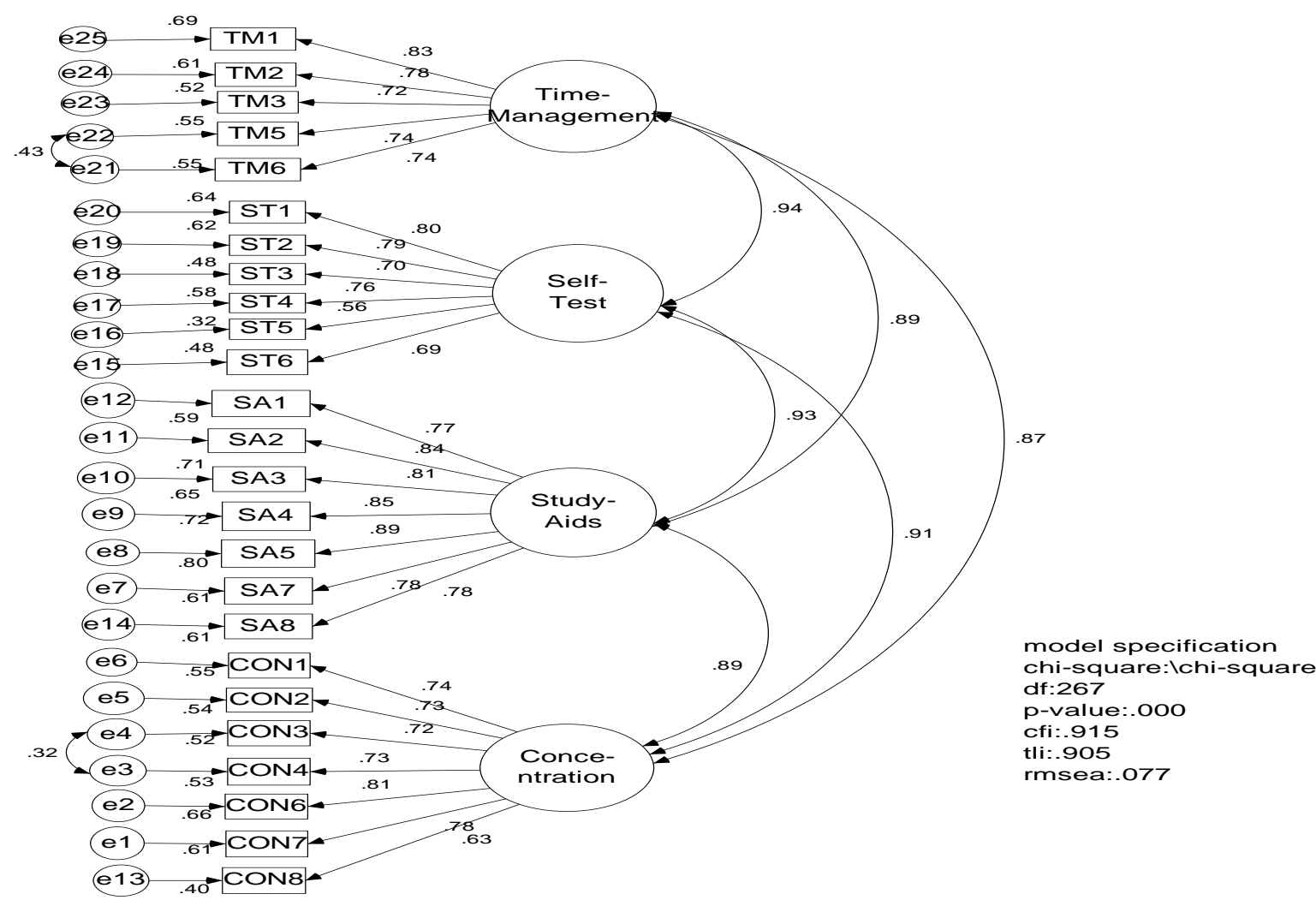

Figure 1

Measurement model and the correlations among latent factors

\section{Comparison of self-learning by gender}

Multivariate analysis of variance (MANOVA) was conducted with gender as the independent variable and the four subscales of selfregulation as dependent variables. The results of MANOVA revealed that male and female students equally used self-regulation skills (Hotelling T2 $(\mathrm{F}=.965)=.428, \mathrm{p}>.05$, squared eta $=.019$ as shown in table 3 .

Table 3

MANOVA Result for Gender Differences on Self-

\begin{tabular}{|c|c|c|c|c|}
\hline \multicolumn{5}{|c|}{ Regulation Subscales } \\
\hline $\begin{array}{l}\text { Self-Regulation } \\
\text { Subscale }\end{array}$ & $\begin{array}{l}\text { Mean } \\
\text { Square }\end{array}$ & $\mathrm{F}$ & Sig. & Eta \\
\hline Concentration & .608 & .698 & .404 & .003 \\
\hline Time Management & .184 & .196 & .658 & .001 \\
\hline Self-Testing & .782 & .981 & .323 & .005 \\
\hline Study Aids & .297 & .381 & .538 & .002 \\
\hline
\end{tabular}

\section{Comparison of Self-Regulation by Age}

Multivariate analysis of variance (MANOVA) was conducted with age as the independent variable and the four subscales of selfregulation as dependent variables. The results of MANOVA revealed that male and female students equally used self-regulation skills $($ Hotelling T2 $(\mathrm{F}=1.793)=.132, \mathrm{p}>.05$, squared eta $=.034)$ as shown in Table 4.
Table 4

MANOVA Result for Age Differences on Self-Regulation

\begin{tabular}{lcccc}
\multicolumn{5}{c}{ Subscales } \\
\hline $\begin{array}{l}\text { Self-Regulation } \\
\text { Subscale }\end{array}$ & $\begin{array}{c}\text { Mean } \\
\text { Square }\end{array}$ & F & Sig. & Eta \\
\hline Concentration & 1.970 & 2.291 & .104 & .022 \\
Time Manage- & 2.220 & 2.412 & .092 & .023 \\
ment & & & & \\
Self-Testing & 1.907 & 2.427 & .091 & .023 \\
Study Aids & 1.481 & 1.922 & .149 & .018 \\
\hline Hotelling T $=(\mathrm{F}=1.793)=.123, \mathrm{p}>.05$, Squared Eta $=.034$
\end{tabular}

\section{Discussion and Conclusion}

According to the findings, the LASSI had a satisfactory reliability and CFA confirmed an acceptable fit of the measurement model to measure self-regulation. The psychometric properties and factor structure of LASSI are consistent with those of LASSI in the study of Weinsten and Palmer (2002). The CFA demonstrates that the four elements of LASSI assessed self-regulation learning in an adequate manner. In other words, these elements measure four different learning strategies of selfregulation. These results are consistent with prior studies such as Weinsten and Palmer (2002).

Based on the results of this research, the relationship among the four elements was significant as these elements are basic skills used 
within the classroom. In this respect, students use university e-learning facilities to revise prior to their lessons. In other words, students are not confined to acquiring knowledge during regular classes or to being in a certain place. In addition to this, university collegesoffer limited seats for students' acceptance following their preparatory year at the university and hence, this may urge students to concentrate during their classes and motivate them to make use of study aids to complete tasks, which will help them recall information during testing. The most crucial skill taught to preparatory year students at the university is taking notes that have to be summarized after their lessons. During the class, students may manage their time by focusing on study aid skills such as taking notes, underlining pertinent information and using charts and graphs to draw up reports. Among the top teaching strategies used in the preparatory program is feedback, because the students who carry out their tasks in the class may underline unfamiliar ideas and obtain the answers from their instructors. The result supports the significant relationship between self-regulation strategies like time management, concentration, studyaids, and self-tests. It can therefore be contended that these strategies are extensively utilized by students while they study their materials and prepare for their tests and assignments. Self-regulated academic learners are recognized by teachers through these skills, and teachers may use this information to categorize students as those who will excel in the subject and those who will not, those who take notes, make comments, ask questions and those who are ready to solve problems. These skills may also assist students in admitting not to know the answer and asking the teacher for ideas in order to succeed in the subject. This study also investigated the differences of self-regulation levels between men and women. In the present study, a difference between men and women did not exist. This may be explained by the notion that students of both genders are concerned with their own needs as well as those of others. Their experiences lead to their greater involvement in the class and activities. In general, students are more likely to take part in self-deprecating humor when tackling adversities and absurdities in order to gain group support. This may be why both male and female students are successful in choosing or developing contexts that suit their personal needs and values, indicating that they possess environmental mastery.

It can further be concluded that the short version of the LASSI is a valid instrument in examining self-regulation strategies used by students in the classroom for it classifies selfregulated learners. The short LASSI is a good instrument to use in future studies owing to its psychometric characteristics and the benefits it offers to researchers. In this regard, Jung (2011) and Lihung (2010) urged researchers to assess the way people with diverse cultural backgrounds perceive the role and importance of self-regulated learning methods. Thus, the SRL short version in this study should be administered to a cross-cultural sample to confirm its stability and validity. Moreover, confirmation may be supported by examining learning groups with different demographics.

On a final note, the short version of the LASSI may be considered invaluable in assessing the academic developmental success of students. Several studies have been dedicated to the educational setting. These studies evidenced that self-regulated learning can lead to the improvement of students' academic achievement and to the facilitation of motivation in learning (Zimmerman \& Martinez-Pons, 2001).

More importantly, information and knowledge concerning self-regulation learning methods are crucial for the development of intervention focused on promoting selfregulated learning methods. For instance, selfregulated learners often employ different strategies while learning, such as organizing and transforming information, elaborating, rehearsing, and memorizing, and reviewing notes, tests and texts; all of these are deemed cognitive learning strategies (Zimmerman \& Martinez-Pons, 2001). While rehearsal is a type of learning that is characterized as a surface method, strategies such as elaboration and organizational transformation are complex methods that call for in-depth processing (Pintrich et al., 1991). In addition to employing different learning strategies, self-regulated learners also utilize meta-cognitive (e.g. monitoring and evaluation of self) and behavioral strategies (time-management and regulation of effort) for performance maintenance. 


\section{References}

Albright, J., \& Park, H. (2009). Confirmatory Factor Analysis Using Amos, LISREL, Mplus, and SAS/STAT CALIS. Working Paper. The University Information Technology Services (UITS) Center for Statistical and Mathematical Computing, Indiana University.

Blair, C., \& Diamond, A. (2008). Biological processes in prevention and intervention: The promotion of self-regulation as a means of preventing school failure. Development and Psychopathology, 20(3), 899-911.

Boekaerts, M. (1993). Being concerned with well-being and with learning. Educational Psychologist, 28, 148-167.

Boekaerts, M. (1999). Self-regulated learning: Where we are today. International Journal of Educational Research, 31, 445-457.

Boekaerts, M., \& Corno, L. (2005). Selfregulation in the classroom: A perspective on assessment and intervention. Applied Psychology: An International Review, 54, 199 231.

Boekaerts, M., Pintrich, P., \& Zeidner, M. (2000). Handbook of self-regulation. San Diego, CA: Academic Press. ISBN: 978-0-12109890-2

Browne, R. (1995). On the use of a pilot sample for sample size determination. Stat Med, 14, 1933-1940.

Bussing, A., Girke, M., Heckmann, C., Schad, F., Ostermann, T., \& Kroz, M. (2009). Validity of the self-regulation questionnaire as a measure of health in quality of life research. European Journal of Medical Research, 14(5), 223-227.

Byrne, B. M. (2010). Structural equation modeling with AMOS: Basic concepts, and programming ( $\left.2^{\text {nd }} \mathrm{Ed}\right)$. Routledge, Tylor \& Francis, New York.

Demetriou, A. (2000). Organization and development of self-understanding and selfregulation: Toward a general theory. In M.Boekaerts, P.R. Pintrich, \& M. Zeidner, Handbook of self-regulation (pp. 209-251). San Diego: Academic Press. http:/ / dx.doi.org/10.1016/B978012109890-2/50036-6
Denissen, J., Wood, D., Penke, L., \& Aken, M. (2013). Self-regulation underlies temperament and personality: An integrative developmental framework. Child Development Perspectives, 7(4), DOI: 10.1111/cdep. 12050

Dogan, T. \& Cetin, B. (2009). The validity, reliability and factorial structure of the Turkish version of the Tromso social intelligence scale. Educational Science: Theory \& Practice, 9(2), 709-720.

Eccles, J. \& Wigfield, A. (2002). Motivational beliefs, values, and goals. Annual Review of Psychology, 53(1), 109-132.

Everson, H., Weinstein, C., \& Laitusis, V. (2000). Strategic learning abilities as a predictor of academic achievement. Paper presented at the annual meeting of the American Educational Research Association, April 2428 , in New Orleans, LA.

Ferrari, J. (2001). Procrastination as selfregulation failure of performance: Effects of cognitive load, self-awareness, and time limits on 'working best under pressure'. European Journal of Personality, 15(5), 391406. Doi: 10.1002/per.413.

Flowers, L., Bridges, B., \& Moore, J. (2011). Concurrent validity of the learning and study strategies inventory (LASSI): A study of African American precollege students. Journal of Black Studies, 2(1), 1-15. DOI: 10.1177/0021934711410881

Gestsdottir, S., \& Lerner, R. (2008). Positive development in adolescence: The development and role of intentional selfregulation. Human Development, 51(3), 202224. Doi:10.1159/000135757.

Hadwin, A., Järvelä, S., \& Miller, M. (2011). Self-regulated, co-regulated, and socially shared regulation of learning. In B. J. Zimmerman \& D. H. Schunk, Handbook of self-regulation of learning and performance (pp. 65-84). New York: Routledge.

Hair, J., Black, W., Babin, B., \& Anderson, R. (2010). Multivariate data analysis. A global perspective (7th Ed). New Jersey: Pearson Education, Inc.

Howell, A.J., \& Watson, D.C. (2007). Procrastination: Associations with achievement goal orientation and learning strategies. Person- 
ality and Individual Differences, 43(1), 167178. doi:10.1016/j.paid.2006.11.017

Huang, F. (2007). Structural Equation Modeling: Theory and Application. Journal of Education and Sciences, 3(1), 1-18.

Jdaitawi, M. (2015). Social connectedness, academic, non-academic behaviors related to self-regulation among university students in Saudi Arabia. International Education Studies, 8(2), 84-100.

Jung, J. (2011). A cross cultural investigation of cognitive, metacognitive and motivational factors affecting student achievement. Unpublished Doctoral Dissertation, the University Of Texas, USA.

Kelloway, E. K. (1998). Using LISREL for structural equation modeling: A researcher's guide $\left(1^{\text {st }} E d\right)$. Thousand Oaks, CA: Sage Publications, Inc.

Kirby, J. R., Silvestri, R., Alklingham, B. H., Parrilla, R., \& La Fave, C. B. (2008). Learning strategies and study approaches of postsecondary students with dyslexia. Journal of Learning Disability, 41(1), 85-96.

Kochanska, G., \& Knaack, A. (2003). Effortful control as a personality characteristic of young children: Antecedents, correlates, and consequences. Journal of Personality, 71(6), 1087-1112. Retrieved April 13, 2015 from

http:/ / onlinelibrary.wiley.com/doi/10.111 1/1467-6494.7106008/pdf.

Kochanska, G., Murray K., \& Harlan, E. (2000). Effortful control in early childhood: Continuity and change, antecedents, and implications for social development. Developmental Psychology, 36(2), 220-232.

Kuhl, J., \& Fuhrmann, A. (2008). Decomposing self-regulation and self-control: The volitional component inventory. In J. Heckhausen \& C. Dweck, (Eds.), motivation and selfregulation across the life-span (3rd ed., pp. 15-45). Cambridge: Cambridge University Press.

Magno, C. (2009). self-regulation and approach to learning in English composition writing. TESOL Journal, 1(16), 1-16.

Marland, J., Dearlove, J., \& Carpenter, J. (2015). LASSI: An Australian evaluation of an enduring study skills assessment tool. Journal of Academic Language and Learning, 9 (2), 3245.

McClelland, M., Cameron, C., Connor, C., Farris, J., Jewkes, A., \& Morrison, F. (2007a). links between behavioral regulation and preschoolers literacy, vocabulary, and math skills. Development Psychology, 43(4), 947959. DOI: 10.1037/0012-1649.43.4.947

Montalvo, F., \& Torres, M. (2004). Selfregulated learning: Current and future directions. Electronic Journal of Research in Educational Psychology, 2(1), 1-34.

Mugera, W. (2013). Non-Probability sampling techniques. Research Methods. University of Nairobi. Retrieved 10 August, 2015 from https://learning.uonbi.ac.ke

Neuman, W. (2004). Basics of social research: Qualitative and quantitative approaches (3 ${ }^{\text {rd }}$ Ed). Boston: Pearson Education, Inc.

Nicol, D., \& Macfarlane-Dick, D. (2006). Formative assessment and self-regulated learning: A model and seven principles of good feedback practice. Studies in Higher Education, 31(2), 199-2018. DOI: 10.1080/03075070600572090.

Nunnally, J. C. (1978). Psychometric Theory. McGraw-Hill Book Company, 86(113), 190255.

Pintrich, P. (1999). The role of motivation in promoting and sustaining self-regulated learning. International Journal of Educational Research, 31(6), 459-470. doi:10.1016/S08830355(99)00015-4

Pintrich, P. (2000). The role of goal orientation in self-regulated learning. In M. Boekaerts, P. Pintrich, \& M. Zeidner (Eds.), Handbook of self-regulation (pp. 451-502). San Diego, CA: Academic Press.

Pintrich, P. R. (2000a). Multiple goals, multiple pathways: The role of goal orientation in learning and achievement. Journal of Educational Psychology, 92(3), 544-555.

Pintrich, P., Smith, D., Garcia, T., \& MaKeachie, W. (1991). A manual for the use of the motivated strategies for learning questionnaire (MSLQ). Ann Arbor: University of Michigan, School of education.

Pintrich, P., Wolters, C., \& Baxter, G. (2000). Assessing metacognition and self-regulated learning. In G.Schraw \& J. C. Ampara 
(Eds.), Issues in the measurement of metacognition (pp. 43-97). Lincoln: Buros Institute of Mental Measurements, University of Nebraska Press.

Posner, M. I., \& Rothbart, M. K. (2000). Developing mechanisms of self-regulation. Development and Psychopathology, 12(2000), 427-441. Retrieved 20 April, from http://www.bowdoin.edu/ sputnam/rot hbart-temperament-

questionnaires/pdf/devel-mech-of-selfreg.pdf

Rothbart, M., Sheese, B., \& Posner, M. (2007). Executive attention and effortful control: Linking temperament, brain networks, and genes. Child Development Perspectives, 1(1), 2-7. DOI: 10.1111/j.1750-8606.2007.00002.x

Sabawi, F. (2007). Future stress among education college students and its relation with gender and major of the study. Educational Faculty Journal, Al-Mousel University Iraq.

Steiger, J. H. (1990). Structural model evaluation and modification: An interval estimation approach. Multivariate Behavioral Research, 25(2), 173-180.

Tsai, M. (2009). The Model of Strategic eLearning: Understanding and Evaluating Student e-Learning from Metacognitive Perspectives. Educational Technology $\mathcal{E}$ Society, 12 (1), 34-48.

Vandevelde, S., Keer, H., \& Rosseel, Y. (2013). Measuring the complexity of upper primary school childrens self-regulated learning: A multi-component approach. Contemporary Educational Psychology, 38(4), 407-425.

Weinstein, C. E. (1994). Strategic learning/strategic teaching: flip sides of a coin. In Pintrich, P. R., Brown, D.R. \& Weinstein C. E. (Eds.) Student Motivation, Cognition, and Learning: Essays in Honor of Wilbert J. McKeachie (pp. 257-273). Hillsdale, NJ: Lawrence Erlbaum.

Weinstein, C., \& Palmer, D. R. (2002). User's manual learning and study strategies inventory. (2nd Ed.). Florida: H\&H Publishing Company, Inc.

Williford, A. P., Whittaker, J. E. V., Vitiello, V. E., \& Downer, J. T. (2013). Children's Engagement Within the Preschool Classroom and Their Development of Self-Regulation.
Early Education and Development, 24, 162187. doi: 10.1080/10409289.2011.628270

Zimmerman, B. J. (2000). Attaining selfregulation: A social cognitive perspective. In. B. Boekaerts, P. R. Pintrich, \& Zeidner (Eds), Handbook of self-regulation (pp. 13-39). San Diego, CA: Academic Press.

Zimmerman, B. \& Martinez-Pons, M. (2001). Achieving academic excellence: $A$ selfregulatory perspective. EnM. Ferrari (Ed.), The Pursuit of excellence through education (pp. 85-110). Mahwah, NJ: Erlbaum.

Zimmerman, B., \& Schunk, D. (2001). Selfregulated learning and academic achievement: Theoretical Perspectives. Hillsdale, NJ: Erlbaum. 